\title{
Perinatal Nitrogen Accretion in Muscles and Fingernails
}

\author{
YVES W. BRANS ${ }^{(19)}$ AND PATRICIA ORTEGA \\ Perinatal Research Laboratories, Departments of Pediatrics, University of Chicago, Chicago, Illinois, and University \\ of Texas Health Science Center at San Antonio, San Antonio, Texas, USA
}

\section{Summary}

Paired triceps muscle and fingernail samples were obtained at autopsy from 25 normally grown (NG) and 16 intrauterine growthretarded (IGR) neonates who died within 28 days of birth. Gestational ages ranged from 21-46 weeks and birthweights ranged from 425-3750 g. Muscle samples were desiccated, defatted and ground to powder. Nitrogen content of muscle and fingernail were determined by a modified micro-Kjeldahl technique. Muscle nitrogen (MN) content averaged $12.1 \pm 1.89 \mathrm{~g} / 100 \mathrm{~g}$ fat-free dry solids (FFDS) (mean \pm SD) and was similar for NG and IGR neonates and, within these two groups, for premature and mature babies. Fingernail nitrogen (FN) content averaged $13.8 \pm 0.95 \mathrm{~g} / 100 \mathrm{~g}$ and no variations with duration and quality of intrauterine growth were identified. Fingernail nitrogen content correlated linearly with muscle nitrogen content in both NG $(n=0.48, P<0.002)$ and IGR $(n=0.67, P<0.005)$ neonates. The regression equation for the entire study population was: $\mathrm{FN}=0.31 \mathrm{MN}+9.96, \mathrm{~S}_{\mathrm{yx}}=$ $\pm 0.778, r=0.59, P<0.001$. These data suggest the possibility of using simple, noninvasive fingernail "biopsies" to monitor protein economy and quality of perinatal growth.

\section{Speculation}

In the perinatal period, $90 \%$ of muscle nitrogen belongs to proteins, which in turn account for $25 \%$ of total body proteins and possibly a larger proportion of mobilizable proteins. Muscle nitrogen content might therefore reflect the status of the body's protein economy and growth. Since fingernail nitrogen content correlates with muscle nitrogen content, fingernails may become a more accessible indicator of underlying metabolic events. Moreover, because of the fingernails' slow rate of growth, their nitrogen content may provide information on metabolic events that occurred several weeks before birth.

Recent studies have illustrated the need to assess the growth and nutritional status of the fetus and neonate qualitatively as well as quantitatively $(4,5)$. Weight gain, the most commonly used indicator of perinatal growth, may reflect increases in water, fat, proteic tissues, or any combination thereof. Fluctuations in body water content may be measured, albeit invasively, by dilution studies. Changes in extracellular water content and in total or subcutaneous body fat may be assessed noninvasively by dynamic skinfold measurements $(3,16)$. Proteinic tissues have eluded all but invasive, biopsy, or surgical techniques. Metabolic balance studies are cumbersome in the neonate and interpretation of their results is limited in subjects who are not in a steady state. Reports of differences in fingernail nitrogen content between neonates and adults as well as between normal and compromised neonates have suggested that fingernail nitrogen content might reflect underlying metabolic events $(13,14)$. The present study was designed in an attempt to establish a relation between fingernail and muscle nitrogen contents. A preliminary report has been presented (2, 17).

\section{MATERIALS AND METHODS}

Paired muscle and fingernail samples were obtained at autopsy from 6 nonmacerated stillborn babies and 35 liveborn neonates who died within 28 days of birth. Gestational age was calculated from the date of the mother's last menstrual period and confirmed whenever possible by physical examination of the baby prior to death (9). Gestation of less than 37 weeks defined prematurity and birthweight below the 10th percentile for gestational age, sex, and race defined IGR (10). Parental consent to sampling various tissues for analytic purposes was obtained with the permit for postmortem examination.

Muscle samples weighing $0.4-6.4 \mathrm{~g}$ were obtained from the triceps immediately after incising the skin. Excess moisture was removed by blotting lightly with a layer of gauze, without compression. The sample was then placed in a preweighed glass vial and weighed on an analytic balance with a reproducibility of $\pm 0.01 \mathrm{mg}$. The sample was then desiccated to constant weight in an oven at $100^{\circ}$, then bathed in petroleum-ether with frequent changes of solvent until the supernatant was clear in order to extract fat. The remaining FFDS were ground to powder for chemical analyses.

One or more entire fingernail was extracted, washed with a nonionic detergent, rinsed several times with double distilled water and dried with acetone.

Muscle and fingernail nitrogen contents were determined by the same modification of micro-Kjeldahl method $(6,14)$. Triplicate aliquots of tissues (1-3 mg FFDS for muscle and $0.5-2 \mathrm{mg}$ fingernail) were digested with sulfuric acid in the presence of a selenium catalyst in a micro-Kjeldahl apparatus. Duplicate aliquots of each digestate were placed in Conway dishes for $2 \mathrm{hr}$ of microdiffusion against a boric acid indicator solution. The indicator solution was then titrated with $0.001 \mathrm{M}$ hydrochloric acid. Nitrogen content was expressed in g/100 g FFDS for muscle and $\mathrm{g} / 100 \mathrm{~g}$ for fingernails.

Student's $t$-test and linear regression analysis were applied to the data.

\section{RESULTS}

Twenty-five of the 41 neonates were NG and 16 were IGR. Characteristics of the two groups are summarized in Table 1. All but 2 of the subjects were black and 16/41 were male. Gestational ages ranged from 21-46 weeks: 9 neonates were mature and 32 were premature, half of them very premature (less than 30 weeks). Birthweights ranged from 425 to $3750 \mathrm{~g}$, with 9 babies weighing more than $2000 \mathrm{~g}, 16$ weighing between 1000 and $2000 \mathrm{~g}$, and 16 weighing less than $1000 \mathrm{~g}$. On the average, IGR neonates were 4 weeks more mature than their NG peers (mean \pm SD: $34 \pm 3.9$ 
Table 1. Characteristics of 41 neonates

\begin{tabular}{lcc}
\hline \multicolumn{1}{c}{ Characteristics } & NG neonates & IGR neonates \\
\hline Number & 25 & 16 \\
Race: white/black & $2 / 23$ & $0 / 16$ \\
Sex: male/female & $9 / 16$ & $7 / 9$ \\
Gestational age' $^{\prime}$ (weeks) & $30 \pm 6.8$ & $34 \pm 3.9$ \\
& $(21-46)$ & $(30-42)$ \\
Birthweight $^{\prime}$ (g) & $1470 \pm 1075$ & $1330 \pm 395$ \\
& $(425-3750)$ & $(790-2080)$ \\
Postnatal age at death' & $2 \pm 4.1$ & $7 \pm 8.6$ \\
(days) & $(0-19)$ & $(0-28)$ \\
\hline
\end{tabular}

'Mean \pm SD (range).

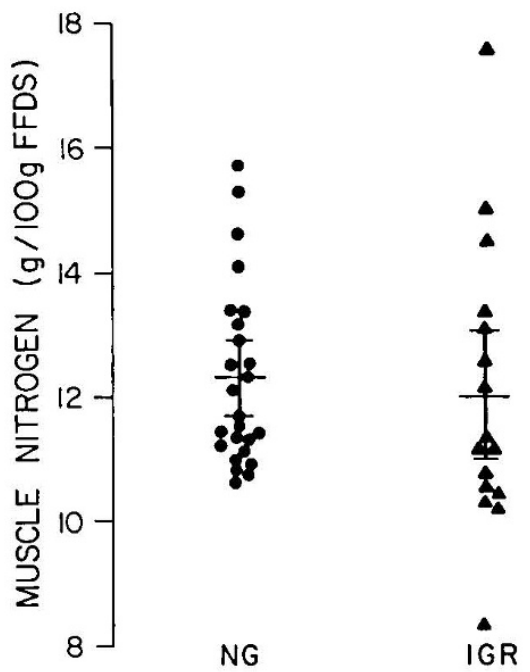

Fig. 1. Nitrogen content ( $\mathrm{g} / 100 \mathrm{~g}$ fat-free dry solids) in muscles from NG (๑) and IGR (A) neonates. Individual values are superimposed on the mean \pm 2 SD for each group.

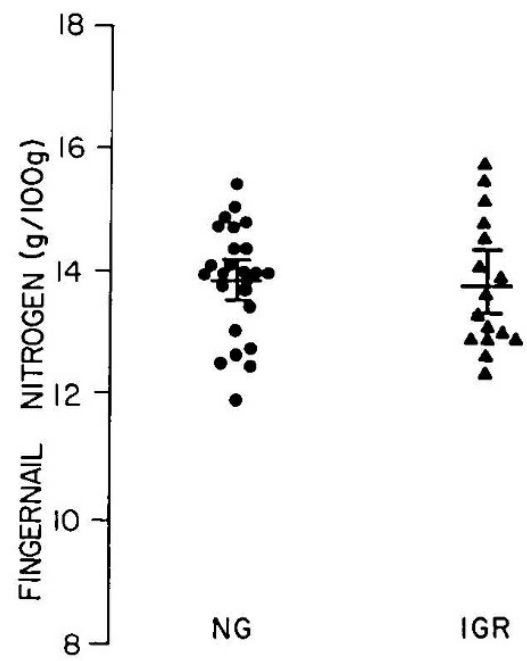

Fig. 2. Nitrogen content $(\mathrm{g} / 100 \mathrm{~g})$ in fingernails from NG $(\bullet)$ and IGR $(\Delta)$ neonates. Individual values are superimposed on the mean \pm 2 SD for each group.

weeks vs. $30 \pm 6.8$ weeks, $P<0.025$ ), but had similar birthweights $(1330 \pm 395 \mathrm{~g} v s .1470 \pm 1075 \mathrm{~g})$. Half of the neonates lived for 24 hr or less beyond birth while only 8 lived more than 1 week. Autopsies were performed within $153 \mathrm{hr}$ of death, 14 being performed within $30 \mathrm{hr}$, and only 9 being delayed until more than $72 \mathrm{hr}$ after death.

Muscle nitrogen content averaged $12.1 \pm 1.89 \mathrm{~g} / 100 \mathrm{~g}$ FFDS. As shown in Figure 1, muscles from IGR neonates contained amounts of nitrogen similar to those from NG babies $(12.1 \pm 0.57$ $\mathrm{g} / 100 \mathrm{~g}$ FFDS vs. $12.3 \pm 0.29 \mathrm{~g} / 100 \mathrm{~g}$ FFDS). Within the NG group, premature and mature neonates had similar mean muscle nitrogen contents $(12.5 \pm 1.59 \mathrm{~g} / 100 \mathrm{~g}$ FFDS and $11.4 \pm 0.78 \mathrm{~g} /$ 100 g FFDS, respectively). Likewise in the IGR group, muscles from premature and mature neonates had similar mean nitrogen contents $(12.0 \pm 2.70 \mathrm{~g} / 100 \mathrm{~g}$ FFDS and $11.7 \pm 1.32 \mathrm{~g} / 100 \mathrm{~g}$ FFDS, respectively).

Fingernail nitrogen content averaged $13.8 \pm 0.95 \mathrm{~g} / 100 \mathrm{~g}$. As shown in Figure 2, IGR neonates had mean fingernail nitrogen contents similar to NG babies $(13.7 \pm 0.27 \mathrm{~g} / 100 \mathrm{~g}$ vs. $13.8 \pm 0.17$ $\mathrm{g} / 100 \mathrm{~g})$. Fingernails from premature $(\mathrm{P})$ and mature $(\mathrm{M})$ neonates contained similar amount of nitrogen on the average, whether the babies were NG (P: $13.8 \pm 0.81 \mathrm{~g} / 100 \mathrm{~g}$; M: $13.6 \pm 1.16 \mathrm{~g} / 100 \mathrm{~g})$ or IGR (P: $13.7 \pm 1.14 \mathrm{~g} / 100 \mathrm{~g}$; M: $13.8 \pm 1.07 \mathrm{~g} / 100 \mathrm{~g}$ ).

The timing of fingernail and muscle sampling in relation to death did not affect nitrogen contents, as shown by horizontal regression lines: Fingernail nitrogen $=0.0010 \mathrm{~T}+13.7(r=0.04)$; muscle nitrogen $=0.0015 \mathrm{~T}+12.1(r=0.03)$, where $\mathrm{T}$ is the length of time(in hours) between death and autopsy.

In NG neonates, fingernail nitrogen content was directly proportional to muscle nitrogen content, with a moderate but significant correlation coefficient of $0.48(P<0.002)$. The two variables correlated even better in IGR neonates, with a highly significant coefficient of $0.67(P<0.005)$. The two regression lines were practically identical (Fig. 3). With data from both groups combined, a correlation coefficient of 0.59 was obtained $(P<0.001)$ and the following regression (Fig. 4): Fingernail nitrogen $=0.31$ muscle nitrogen $+9.96 ; S_{y x}= \pm 0.778$.
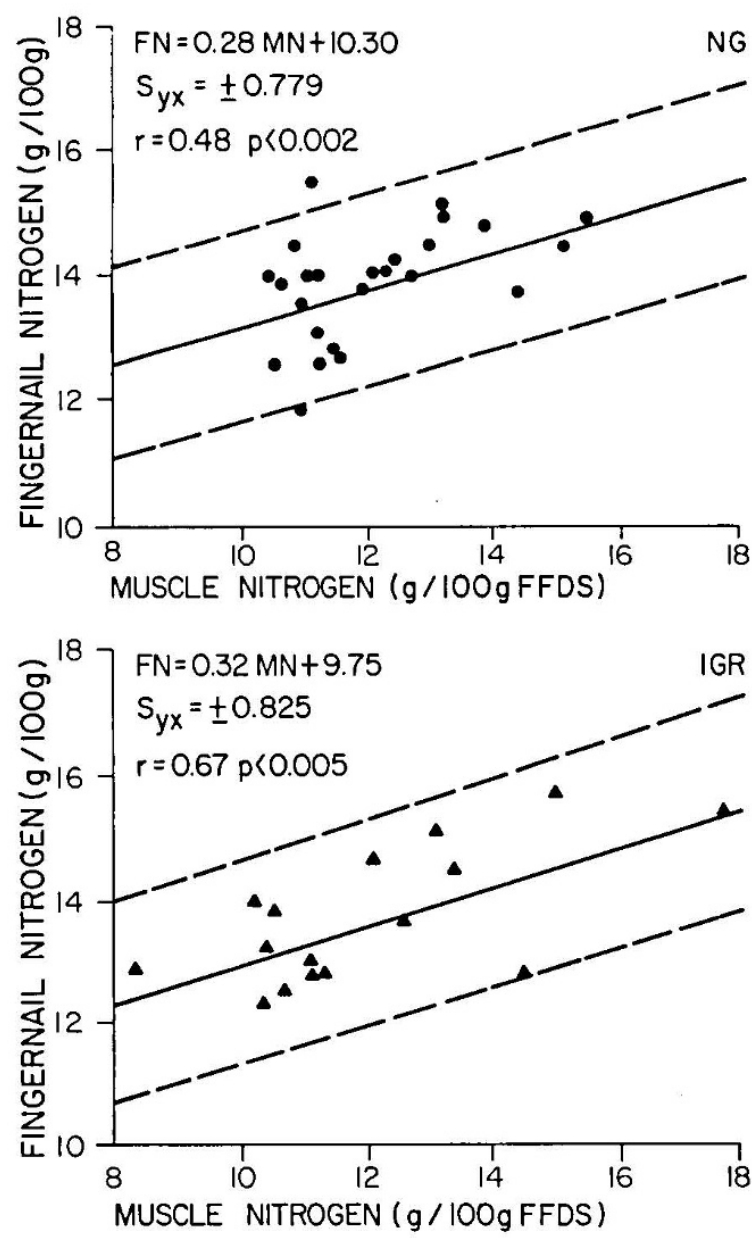

Fig. 3. Relation between fingernail nitrogen content (FN) and muscle nitrogen content $(\mathrm{MN})$ in NG and IGR neonates. Individual values are superimposed on the regression line $\pm 2 \mathrm{~S}_{\mathrm{yx}}$. 


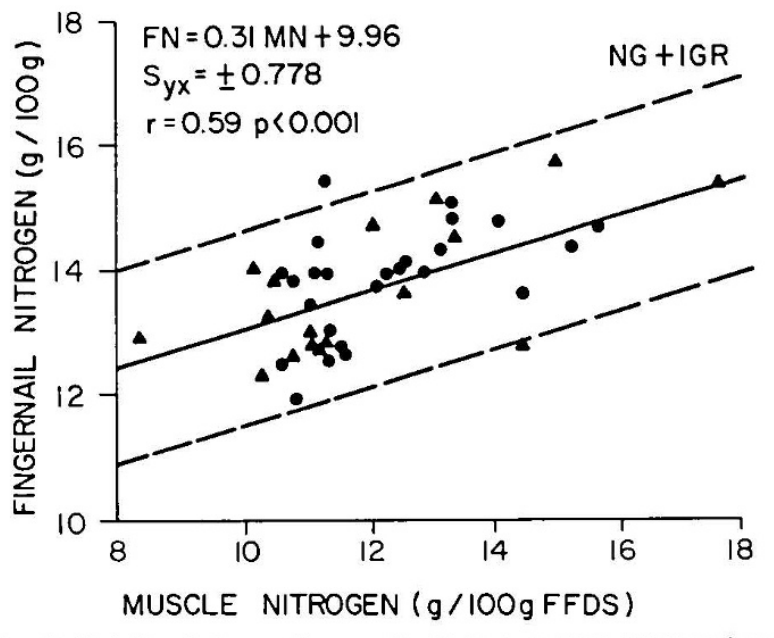

Fig. 4. Relation between fingernail nitrogen content (FN) and muscle nitrogen content $(\mathrm{MN})$ in neonates. Individual values are superimposed on the regression line $\pm 2 \mathrm{~S}_{\mathbf{y x}}$.

\section{DISCUSSION}

The general state of health and metabolic activity has been known to affect fingernail composition in adults. The amount of nitrogen lost in dermal excretions of which fingernails are an important portion, decreases in normal subjects when daily dietary intake of nitrogen decreases and increases when nitrogen intake increases (15). Fingernail creatinine content increases in patients with chronic renal failure (12). In healthy mature neonates, fingernail trimmings obtained within 2 weeks of birth contain on the average less nitrogen than fingernails from healthy adults (13.6 $\pm 0.96 \mathrm{~g} / 100 \mathrm{~g}$ vs. $14.6 \pm 0.59 \mathrm{~g} / 100 \mathrm{~g}, P<0.001)(14)$. Mean nitrogen content is lower in fingernail clippings from "compromised" neonates-P and IGR babies, neonates with perinatal asphyxia and Coombs positive hemolytic anemia, and infants of diabetic or toxemic mothers-than in clippings from healthy mature neonates $(12.3 \pm 1.66 \mathrm{~g} / 100 \mathrm{~g}$ vs. $13.6 \pm 0.96 \mathrm{~g} / 100 \mathrm{~g}$, $P<0.001)(14)$. Our earlier data suggest that prematurity itself does not affect mean fingernail nitrogen content (13.0 \pm 1.46 $\mathrm{g} / 100 \mathrm{~g}$ in $\mathrm{P}$ neonates $v s .13 .4 \pm 1.29 \mathrm{~g} / 100 \mathrm{~g}$ in M neonates) (13). IGR neonates, however, have lower nitrogen content in fingernail clippings obtained within 21 days of birth than their NG peers $(12.3 \pm 1.46 \mathrm{~g} / 100 \mathrm{~g} v s .13 .3 \pm 1.34 \mathrm{~g} / 100 \mathrm{~g}, P<0.005)$. Infants of diabetic mothers have even lower fingernail nitrogen content than NG babies $(11.6 \pm 1.31 \mathrm{~g} / 100 \mathrm{~g}$ vs. $13.3 \pm 1.34 \mathrm{~g} / 100 \mathrm{~g}$, $P<0.001$ ), but not significantly lower than IGR babies (13).

The data from the present study apparently contradict our earlier findings, since no difference in nitrogen content was found between fingernails from IGR and NG neonates. This may be the result of using entire fingernails rather than clippings. No information is available concerning the rate of fingernail growth in the fetus and neonate. A 1000-g neonate's fingernails extend approximately $3 \mathrm{~mm}$ from the nail bed to the distal edge. At an adult fingernail's maximum growth of $0.11 \mathrm{~mm} /$ day (15), this represents 27 days of growth. Depending on the nature of the perinatal course, a fingernail could be described as a succession of zones with different nitrogen concentrations. The nitrogen content of corresponding zones of two neonates' fingernails (e.g., their distal edge) may be different while the entire fingernails' mean nitrogen concentrations are similar. Interestingly, no difference was found between amino acid patterns and concentrations of NG and IGR neonates' entire hair growth (1). The mean composition of fingernails and hair might thus be an integrator of events occurring over a period of several days or weeks while the appendage is growing, and the result of our two studies need not be contradictory. The final proof would be difficult to elicit in view of the technical problems involved in measuring reproducibly nitrogen content of very small amounts of fingernails (a 1000-g neonate's entire nail weighs about $0.5 \mathrm{mg}$ ).
Further speculation on the meaning of fingernail nitrogen content requires quantitative distinction between nonprotein (urea, creatinine) and protein ( $\alpha$-amino) nitrogen. No data for fingernail nonprotein content exist in neonates. A healthy adult's fingernail creatinine content of at most $7 \mathrm{mg} / 100 \mathrm{~g}$ would account for about $0.5 \%$ of total fingernail nitrogen (12). It appears that nonprotein nitrogen content of fingernails would be negligible.

Data on the chemical composition of muscles in human neonate are scarce. The entire thigh muscle has been analyzed in seven fetuses ranging from 13-22 weeks of gestation and four mature stillborn neonates (8). Nitrogen content averages $11.9 \mathrm{~g} / 100 \mathrm{~g}$ FFDS and protein nitrogen accounts for $89 \%$ of the total. In Macaca mulatta fetuses ranging from 80-160 days of gestation (term), skeletal muscle nitrogen content averaged $12.4 \mathrm{~g} / 100 \mathrm{~g}$ FFDS approximately (individual values estimated from a graph) and remained quite stable throughout that period of gestation (7). Our own values are quite similar $(12.1 \pm 1.89 \mathrm{~g} / 100 \mathrm{~g}$ FFDS $)$. The absence of difference in nitrogen content of muscle from IGR and NG neonates may be surprising, but it is in keeping with existing findings in the rhesus monkey (11). IGR appears to be reflected more in the size than in the chemical composition of skeletal muscles.

Skeletal muscles account for $25 \%$ of total body proteins in the neonate and probably for a greater proportion of mobilizable proteins (8). They play an important role as endogenous suppliers of nitrogen when the exogenous (dietary or transplancental) supply is insufficient. However, these organs are accessible only by invasive techniques, biopsy, or surgery. The correlation between nitrogen content of muscle and fingernail suggests that the latter may be used to assess the former noninvasively. More data are needed to define the significance of these findings. Under clinical conditions, only fingernail clippings are available noninvasively. The relationship between mean nitrogen content of an entire nail and the nitrogen concentrations of various zones of a fingernail need to be defined. Because of the slow growth rate of fingernails, the composition of nail clippings at, or shortly after, birth may reflect the influence of events that occurred days or weeks before birth. The study of fingernail growth rates will be of obvious importance to the timing of these events. Specifically, potential variations in the rate of fingernail growth under various states of nutrition must be studied as the important variable may well be the amount of nitrogen deposited in a fingernail per unit of time rather than its nitrogen concentration.

\section{CONCLUSION}

Muscle and fingernail nitrogen contents vary neither with duration nor quality of intrauterine growth. Fingernail nitrogen content appears to correlate moderately but significantly with muscle nitrogen content $(r=0.59, P<0.001)$. This suggests that fingernails may be used to monitor muscle nitrogen content without recourse to invasive techniques. Since muscle nitrogen accounts for $25 \%$ of total body nitrogen and possibly a greater proportion of mobilizable nitrogen, fingernail nitrogen content may reflect the status of the body's protein economy. Since fingernail clippings represent nail formed several weeks earlier, they further constitute noninvasive intrauterine biopsies.

\section{REFERENCES AND NOTES}

I. Baum, J. D., Hughes, E. A., and Harris, D. A.: Neonatal hair as a record of intrauterine nutrition. Biol. Neonate, 25: 208 (1974).

2. Brans, Y. W., and Ortega, P: Neonatal fingernails and muscles: Correlation between nitrogen contents. Clin. Res., 25: 79A (1977).

3. Brans, Y. W., Sumners, J. E., Dweck. H. S., and Cassady, G: A noninvasive approach to body composition in the neonate: Dynamic skinfold measurements. Pediat. Res., 8: 215 (1974).

4. Brans, Y. W., Sumners, J. E., Dweck, H. S., Bailey, P. E. and Cassady G. Feeding the low birth weight infant: orally or parentally? II. Corrected bromide space in parenterally-supplemented infants. Pediatrics, 58: 809 (1976).

5. Brans, Y. W., Sumners, J. E., Dweck, H. S., and Cassady, G.: Feeding the low birth weight infant: orally or parenterally? Preliminary results of a comparative study. Pediatrics, 54: 15 (1974).

6. Cheek, D. B.: Human Growth: Body Composition, Cell Growth Energy and 
Intelligence, p. 661 (Lea \& Febiger, Philadelphia, 1968).

7. Cheek, D. B., and Scott, R. E.: Growth of skeletal and cardiac muscle. In: D. B. Cheek: Fetal and Postnatal Cellular Growth: Hormones and Nutrition, p. 243 (J. Wiley \& Sons, New York, 1975).

8. Dickerson, J. W. T., and Widdowson, E. M.: Chemical changes in skeletal muscle during development. Biochem. J., 74: 247 (1960).

9. Dubowitz, L. M. S., Dubowitz, V., and Goldberg. C.: Clinical assessment of gestational age in the newborn infant. J. Pediat., 77: I (1970).

10. Freeman, M. G., Graves, W. L., and Thompson, R. L.: Indigent Negro and Caucasian birth-weight-gestational age tables. Pediatrics, 46: 9 (1970).

11. Hill, D. E.: Experimental growth retardation in rhesus monkeys. In: K. Elliott, and J. Knight: Size at Birth, p. 108 (Associated Scientific Publishers, Amsterdam, 1974).

12. Levitt, J. I.: Creatinine concentration of human fingernail and toenail clippings. Ann. Int. Med., 64: 312 (1966).

13. Lockard, W., Brans, Y., Sumners, J., Dweck, H., and Cassady, G.: Fingernail nitrogen accretion in the fetus and newborn. Pediat. Res.. 7: 176 (1973).
14. Lockard, D., Pass R., and Cassady, G.: Fingernail nitrogen content in neonates. Pediatrics, 49: 618 (1972).

15. Sirbu, E. R., Margen, S., and Calloway, D. H.: Effect of reduced protein intake on nitrogen loss from the human integument. Amer. J. Clin. Nutr., 20: 1158 (1967).

16. Sumners, J., Burris, S., and Arkans, H.: Compressibility of the skinfold-An index of extracellular volume. Pediat. Res., 10: 360 (1976).

17. This study was presented in part at a meeting of the Southern Society for Pediatric Research, New Orleans, Louisiana, January 1977.

18. This research was supported in part by grants from The Louis Block Fund, University of Chicago, from The Home for Destitute and Crippled Children, Chicago, and from Mead Johnson Laboratories, Evansville, Indiana.

19. Requests for reprints should be addressed to: Yves W. Brans, M.D., Department of Pediatrics. University of Texas Health Science Center at San Antonio. 7703 Floyd Curl Drive, San Antonio. TX 78284 (USA).

20. Received for publication August 3, 1977.

21. Accepted for publication October $26,1977$. 